fall into grades I and II, and $20 \%$ into grade III. Only one patient of the 110 interviewed said that he was worse after the operation, and the sole patient with an

\begin{tabular}{|c|c|c|c|c|}
\hline \multicolumn{5}{|c|}{ TABLE III } \\
\hline $\begin{array}{ll}\text { Visick grading } \\
\text { No. of patients }\end{array}$ & $35(31 \cdot 8 \%)$ & $51(46 \cdot 5 \%)$ & $22(19.9 \%)$ & $\underset{2(1.8 \%)}{\text { IV }}$ \\
\hline
\end{tabular}

anastomotic ulcer has also been placed in Grade IV. Even the $20 \%$ with a relatively unsatisfactory result were all of the opinion that they were far better than in the days of their ulcer.

\section{Summary}

A review is given of 128 patients with duodenal ulcers treated during $1950-4$ by a limited Polya gastrectomy ; $110(86 \%)$ patients were interviewed.

Only half the stomach was removed.

The importance of ligating the vasa brevia to reduce the gastric acidity is emphasized.

Only one patient $(0.8 \%)$ developed an anastomotic ulcer.

The incidence of the dumping syndrome was much lower than with the standard three-quarters gastrectomy.

Bile vomiting occurred in $23 \%$ of the series, but was severe in only one woman.

Iron-deficiency anaemia was present in $65 \%$ of the men.

Loss of weight occurred in $92 \%$ of the patients. There was no correlation between the result of the operation and the amount of weight lost.

We are grateful to Miss Turner, M.A., the senior almoner, without whose help and ingenuity it would have been impossible to trace many of the patients. We are also indebted to the general practitioners of Oxford who also went to great trouble in helping us to find the patients.

\section{REPERENCES}

Armstrong, R. A., and Penick, R. M. (1960). Ann. Surg., 152 109.

Baird. I. M., Blackburn, E. K., and Wilson, G. M. (1959). Quart. J. Med.. 28, 21 .

Blake, J., and Rechnitzer, P. A. (1953). Ibid., 22, 419.

Bloomfield. A. L., and Polland, W. S. (1933). Gastric Anacidity, p. 95. Macmillan, New York.

Brookes, V. S., Waterhouse, J. A. H., and Thorn, P. A. (1960), Gut, 1, 149

Bruce. J.. Card, W. I., Marks, I. N., and Sircus, W. (1959). Ann. roy. Coll. Surg. Edinb., 4, 85.

Capper, W. M., and Welbourn, R. B. (1955). Brit. J. Surg., 43 24.

Conyers, J. H., Hall, R. A., Laing, D., Pulvertaft, C. N., and Willson-Pepper, J. K. (1960). Brit. Jै. Surg.. 47, 533.

Custer, M. D.. Butt, M. R., and Waugh, J. M. (1946). Ann. Surg.. 123. 410.

Davey, W. W. (1959). Ann. roy. Coll. Surg. Engl., 24, 277.

Duthie, H. L. (1960). Scot. med. J., 5, 127.

Glazebrook, A. J., and Welbourn, R. B. (1952). Brit. J. Surg., 40. 111 .

Gordon-Taylor, G., Hudson, R. V., Dodds, E. C., Warner, J. L., and Whitby, L. (1928). Ibid., 16, 641.

Hallwright, W. W (1957). In The Management of Abdominal Operations, 2nd ed., edited by R. Maingot, p. 738. Lewis, London.

Hartfall, S. J. (1934). Guy's Hosp. Rep.. 84, 448.

Hey, W. H. (1937). Proc. interst. Postgrad. med. Assembl., p. 291.

Hobsley, M., and Le Quesne, L. P. (1960). Brit. med. J., 1, 147

Hurst, A. F (1913). Ann. Surg.. 58, 466.

Illingworth, C. F. W (1960). Gut, 1, 183.

Johnston. I. D. A., Welbourn, R., and Acheson, K. (1958). Lancet. 1. 1242

Lyngar, E. (1950). Acta med. scand., Suppl. 247.

MacLellan, E. (1951). Lancet, 1, 257.
Mix, C. L. (1922). Surg. Clin. N. Amer., 2, 617.

Pulvertaft, C. N. (1952). Lancet, 1, 225.

Somervell, T. H. (1943). Brit. J. Surg., 30, 113.

- (1948). The Surgery of the Stomach and Duodenum p. 271. Arnold, London.

Visick, A. H. (1948). Lancet, 1, 505.

Wells, C., and Johnston, J. H (1956). Ibid., 2, 479.

- and MacPhee, I. W. (1954). Brit. med. J., 2, 1128.

- and Welbourn, R. (1951). Ibid., 1, 546.

Witts, L. J. (1956). Anaemia and the Alimentary Tract, Sydney Watson Smith Memorial Lecture, 1955, Royal College of Physicians, Publication No. 7. Edinburgh.

Wollaeger. E. E., Comfort, M. W., and Weir, J. F., and Osterberg, A. E. (1946). Gastroenterology, 6, 83.

Wood, W. Q. (1949). Arch. Surg., 58, 455.

Zollinger, R. M., and Ellison, E. H. (1954). J. Amer. med. Ass. 154, 811.

— and Hoerr, S. O. (1947). Ibid., 134, 575.

\section{STEATORRHOEA IN PROGRESSIVE SYSTEMIC SCLEROSIS (SCLERODERMA)}

\author{
BY
}

D. J. McBRIEN, M.B., M.R.C.P.

Senior Medical Registrar, St. Thomas's Hospital, London AND

\section{H. E. LOCKHART MUMMERY, M.D., M.Chir. F.R.C.S.}

Consultant Surgeon, St. Thomas's Hospital, London

The purpose of this paper is to draw attention to the fact that progressive systemic sclerosis may present as the malabsorption syndrome or as subacute smallintestinal obstruction in the absence of obvious skin manifestations of the disease.

The continued use of the term "scleroderma" is misleading in that it tends to focus attention on the external manifestations, which, if absent, may prevent the correct diagnosis being considered. For this reason we suggest the use of the term "progressive systemic sclerosis," as originally put forward by Goetz (1954).

\section{Case Report}

A married woman of 43 was first seen in 1954 for an episode of epigastric pain and vomiting. A barium-meal examination showed oesophageal reflux without a hernia and a possible duodenal ulcer. Cholecystogram was normal. In February, 1960, she was seen by a neurologist on account of difficulty in walking for three months. A tentative diagnosis of disseminated sclerosis was made and she was treated with vitamin $B_{12}$ and prednisone. In September, 1960, she was admitted to the Royal South Hants Hospital under the care of Dr. K. Robertson, complaining of nausea, vomiting, diarrhoea, and loss of weight. She mentioned that there was a sensation of food sticking at the level of the lower end of the sternum. On questioning she admitted to Raynaud's phenomenon for about a year, the attacks occurring spontaneously, not particularly on exposure to cold.

Dr. Robertson thought the appearance of the fingers was suggestive of progressive systemic sclerosis.

Investigation revealed a gross steatorrhoea but no anaemia. The glucose-tolerance curve was flat. X!lose tolerance was normal. Plasma proteins showed a low albumin of $2 \mathrm{~g} .1$ $100 \mathrm{ml}$. Electrolytes were normal. Barium-meal examination showed gross dilatation of the small intestine. Biopsy of skin of hand was normal. A diagnosis of steatorrhoea possibly secondary to scleroderma was made. The patient 
was treated with a gluten-free diet, iron, folic acid, vitamins, and later prednisone. There appeared to be no response to this treatment, and finally she was readmitted, much deteriorated, with profuse diarrhoea and vomiting.

On May 11, 1961, she was transferred to St. Thomas's Hospital under the care of Dr. B. Creamer. At this time she was a very ill woman of 50 , the loss of weight now amounting to 7 stone $(44.5 \mathrm{~kg}$.) over two years.

The skin showed generalized pigmentation but was not obviously thickened apart from a suspicious area at the side of the neck. The mouth appeared normal in size and there were no telangiectases. Dr. G. C. Wells felt unable to commit himself to a diagnosis of progressive systemic sclerosis solely on the appearance of the skin. In retrospect it was noted that the skin of the forearms fitted the underlying tissues surprisingly well considering the gross loss of weight.

The abdomen was distended and tympanitic and the patient complained bitterly of the sensation of fullness with much rumbling and gurgling. The tongue was raspberrycoloured but not depapillated. Apart from marked musclewasting there was no abnormality in the central nervous system. Micturition occurred chiefly at night, a point noticed by the patient, and tests confirmed that she was unable to handle a water load normally.

\section{Investigations}

Biochemical.-Stool fat (4 days), 17 g./24 hours. Plasma electrolytes: persistently low potassium, in the region of $2 \mathrm{mEq} / \mathrm{l}$., but otherwise normal. Blood urea, $25 \mathrm{mg} . / 100 \mathrm{ml}$. Histamine test meal normal. Serum calcium, $7.8 \mathrm{mg} . / 100$ $\mathrm{ml}$; serum phosphorus $3.3 \mathrm{mg} . / 100 \mathrm{ml}$. Plasma proteins: total $5.4 \mathrm{~g} . / 100 \mathrm{ml}$. (albumin $4 \mathrm{~g}$., globulin $1.4 \mathrm{~g}$.). Electrophoresis showed slight rise in alpha-2 globulins. Xylose tolerance normal. Formiminoglutamic acid test (Figlu): after $20 \mathrm{~g}$. of histidine the urine contained no excess Figlu. Serum creatine, $1.1 \mathrm{mg} . / 100 \mathrm{ml}$. Urine contained no porphobilinogen or uroporphyrins.

Haematology.-Haemoglobin, 89\%. W.B.C., 9,300/c.mm. ; normal differential. E.S.R., $59 \mathrm{~mm}$./ hr. (Westergren); this later dropped to $10 \mathrm{~mm}$./hr., and was thought to be associated with a transient urinary infection. Sternal marrow normal.

Bacteriology.-Escherichia coli urinary infection. Stool culture revealed no pathogens.

Water-load Test.-After drinking 1 litre of water the hourly urine volumes were: $10 \mathrm{ml}$., $50 \mathrm{ml}$., $50 \mathrm{ml}$., $50 \mathrm{ml}$.

Radiology.-Small-bowel meal (May 23): Fig. 1 shows gross dilatation of duodenum and proximal jejunum with much fluid in the dilated loops and very slow transit through them. The ileum is only poorly shown, but in the 24-hour film there is a loop of bowel which apparently represents terminal ileum. This is of normal calibre but abnormal mucosal pattern.

Pressure studies of oesophageal motility demonstrated the typical lack of peristaltic activity in the lower two-thirds of the oesophagus found in progressive systemic sclerosis (Dornhorst et al., 1954). Peroral biopsy of the small intestine showed a normal mucosal pattern. Biopsy of the skin from a suspicious area at the side of the neck showed the typical changes of progressive systemic sclerosis.

Although it was apparent that the patient had some features of progressive systemic sclerosis it was felt that the possibility of some unrelated small-bowel lesion particularly causing subacute obstruction could not be excluded and therefore a laparotomy was performed by one of us (H. E. L. M.). This revealed a grossly dilated duodenum and loops of proximal jejunum which gradually tapered down to a normal ileum. There was no obstruction or pathological glands, and the other organs appeared normal. Full-thickness biopsies were taken from the dilated jejunum and from the normal ileum.
The histology of the jejunum (Fig. 2) showed atrophy of the muscle coats but a normal mucosa apart from infiltration with chronic inflammatory cells. The ileum appeared normal.

The patient continued to deteriorate steadily, with uncontrolled diarrhoea, distension, and periodic vomiting.

An attempt was made to alter the flora of the small intestine by a course of tetracycline $250 \mathrm{mg}$. q.d.s. for a week. This resulted in obvious improvement clinically and appeared to be confirmed by a stool fat of $7.2 \mathrm{~g} . / 24 \mathrm{hr}$.

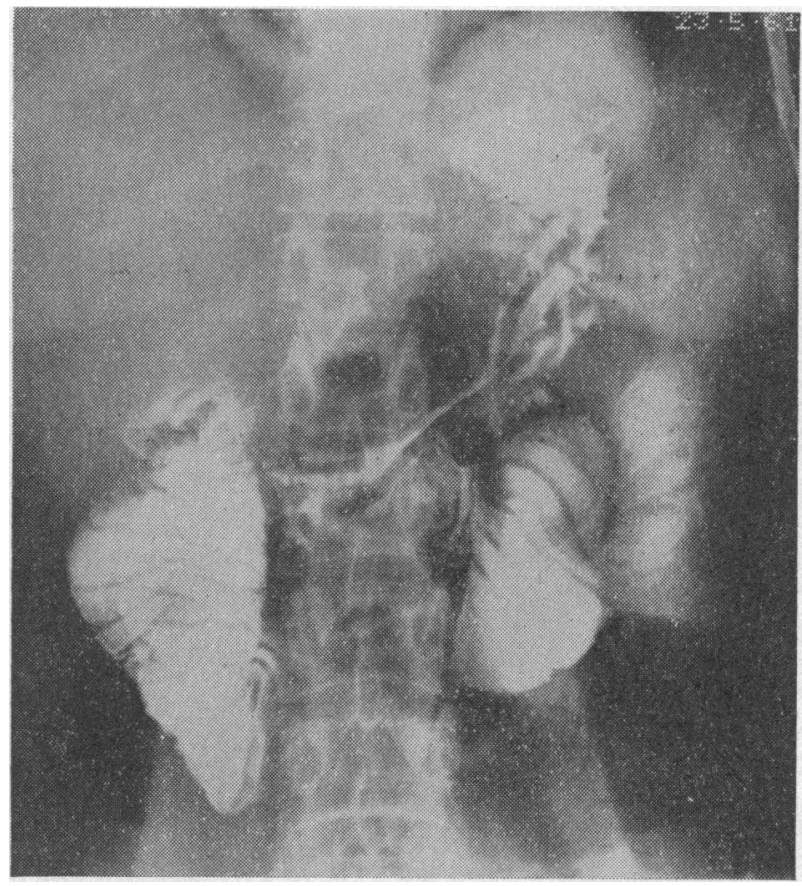

Fig. 1.-Barium-meal radiograph showing gross dilatation of the duodenum and upper jejunum.

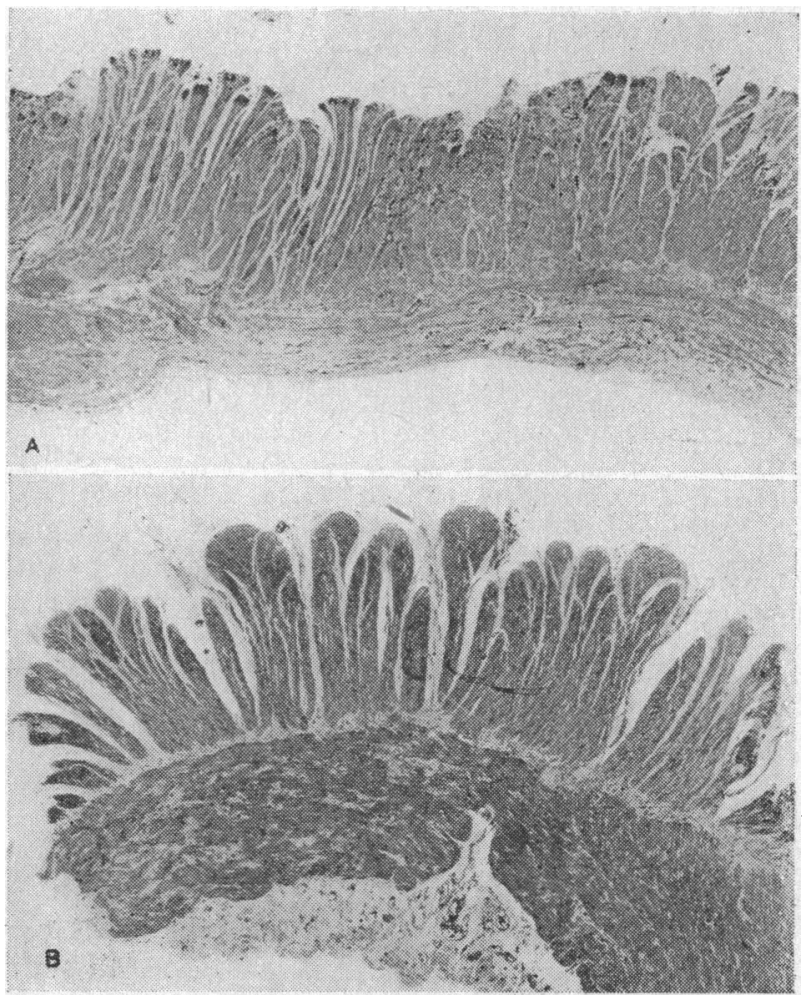

Fig. 2.-A, jejunum, B, ileum, to show atrophy of muscle coats. Mucosa is not shown. 
The pattern of water excretion after a load of 1 litre returned to normal. After an interval the course of tetracycline was repeated, but with disappointing results.

By now it was apparent that the patient was losing ground so rapidly that death would ensue in a matter of months if the process continued. It seemed that her real disability was due to malabsorption, and this in turn stemmed from a lack of peristaltic activity in the upper small bowel, which was converted into a stagnant reservoir. It was therefore decided to resect the affected portion of jejunum. This was done on July 26 . The abnormal jejunum was resected up to the level of the duodeno-jejunal flexure. The reconstruction consisted of a retrocolic side-to-end gastrojejunostomy and an end-to-side duodeno-jejunostomy.

Immediate recovery from the operation was uneventful but the patient gradually became very oedematous over the next three weeks. Without the use of diuretics there then followed a vast spontaneous diuresis in which she lost over a stone $(6.4 \mathrm{~kg}$.) in weight. The change in her was most dramatic. She developed a voracious appetite, the abdominal discomfort disappeared, and her bowels now opened on average twice a day with well-formed motions. Of some interest was the return of the water excretion to a normal pattern once more.

The patient was finally discharged on September 14 on no medication. When seen in January, 1962, six months after the operation, her weight had continued to rise, and she was leading a normal life.

Histology of the Resected Specimen.-A piece of small bowel $120 \mathrm{~cm}$. long, considerably dilated throughout its length, one end being dilated more than the other and being approximately $11 \mathrm{~cm}$. in diameter. Sections showed atrophy and patchy necrosis of both muscle layers. The mucosa showed a normal pattern, but was heavily infiltrated with chronic inflammatory cells.

\section{Discussion}

\section{Skin Changes}

Visceral involvement without skin changes is generally thought to be rare. Most authors take the view that gastro-intestinal lesions appear late in the natural history of the disease. There are, however, a number of examples in the literature where the skin changes have been recorded as either absent or so minimal that they have not led to the recognition of the disease. Hale and Schatzki (1944) reported the case of man of 61 in whom the changes in the hands were recognized only in retrospect as being due to progressive systemic sclerosis.

Marshall (1956) in reporting three cases which came to laparotomy noted that in one there were no clinical signs of progressive systemic sclerosis and in another Raynaud's phenomenon came to light only after the operation. Herrington (1956) stated that no skin changes were seen in a case coming to operation for subacute obstruction. Sommerville et al. (1959) in a review of 11 cases of progressive systemic sclerosis of the small intestine mentions one case in which there were no skin changes or Raynaud's phenomenon. Crown (1961) described a fatal case with visceral involvement without any external manifestations of progressive systemic sclerosis.

\section{Radiology}

The radiological appearances of the small bowel have been recognized for many years. Hale and Schatzki (1944) gave an excellent account, and their findings were confirmed by Pugh (1948). Others have since reported similar findings.
The changes consist in gross dilatation of the second and third parts of the duodenum with large dilated loops of jejunum. The appearances in the jejunum are very similar to those found in idiopathic steatorrhoea, but the striking changes in the duodenum are not seen in idiopathic steatorrhoea and are probably pathognomonic of diffuse systemic sclerosis.

Unfortunately dilatation of the duodenum is not always present (Herrington, 1959 ; Horswell et al., 1961).

\section{Steatorrhoea}

Rosenthal (1957) presented four cases of progressive systemic sclerosis complicated by steatorrhoea, giving the details of one case coming to necropsy. He reviewed previous reports of cases but was unable to find any with detailed observations. Horswell et al. (1961) presented a case in which the chief problem was the malabsorption syndrome.

Our patient was disabled largely by the steatorrhoea and apparent subacute obstruction.

The mechanism of the malabsorption is of some interest. Rosenthal (1957) suggested that it was due to the severe mucosal changes seen in his case, although he thought it likely to have been aggravated by the stasis produced by atrophy of the muscle coats. In our case, as is usual in this disease, the mucosa was normal in biopsy and laparotomy specimens. We feel that the malabsorption in our case could be explained by stagnation of the contents of the upper small bowel leading to an altered bowel flora. There is some evidence for this in that the degree of steatorrhoea was reduced to nearly normal by the use of tetracycline. The process is probably similar to that found in the blind-loop syndrome, multiple jejunal diverticulosis, and the subacute obstruction found in some cases of Crohn's disease.

\section{Surgery}

We have found only three records of previous cases in which the upper small intestine has been resected in progressive systemic sclerosis.

The first was reported by Hale and Schatzki (1944). The patient was a man of 61 with a two-months' history of nausea, vomiting, and cramping pains in the epigastrium. Barium-meal examination showed a normal oesophagus ; the third part of the duodenum was greatly dilated, and after a long delay two grossly dilated loops of jejunum were filled. These appearances were interpreted as due to obstruction. Laparotomy revealed $65 \mathrm{~cm}$. of dilated jejunum of a greyish colour. In addition to the generalized dilatation there were individual saccular dilatations. The jejunum tapered gradually into normal-appearing bowel. About $80 \mathrm{~cm}$. of the affected bowel was resected. The patient died 34 days later with pulmonary oedema, but during this time he continued to have symptoms of subacute obstruction. Marshall (1956) reported the first successful case of resection. The patient was a man of 57. Between 240 and $300 \mathrm{~cm}$. of jejunum was resected, with end-to-end anastomosis. The result was successful Initially an exploratory laparotomy was done in order to make a diagnosis, but after seven months' deterioration resection was carried out. Herrington (1959) gave a full account of the case of a man aged 55, without skin changes, who presented as a problem of subacute obstruction. The aetiology was thought to be obscure. An extensive resection of the jejunum and upper ileum 
was carried out with end-to-end anastomosis of the bowel. After 18 months' follow-up the patient was well.

The decision to advise resection in our patient was made after considerable hesitation, particularly in view of the result in Hale and Schatzki's (1944) case, where the obstruction persisted. We thought that the reason for this was that anastomosis of the normal ileum to the abnormal duodenum resulted in a functional block to peristalsis. For this reason, in our case the ileum was anastomosed to the stomach, the duodenum being implanted end-to-side into the ileum.

We are not suggesting that we have in any way cured this patient, but that surgery has afforded relief of a serious complication which gives rise to gross disability that would probably have resulted in very early death.

ADDENDUM.-The patient remained in good health until about July, 1962, when she deteriorated, dying suddenly at the end of that month.

\section{Summary}

A case is reported of progressive systemic sclerosis presenting as malabsorption and subacute obstruction, surgical relief being given by resection of the affected segment of small intestine.

The relevant literature is reviewed.

A plea is made for the term "progressive systemic sclerosis" in preference to "scleroderma" on the grounds that the latter may act as a diagnostic barrier.

We are grateful to Dr. Kenneth Robertson, who first suggested the correct diagnosis in this case, and who referred the patient to St. Thomas's Hospital; and to Dr. Brian Creamer, under whose care the patient was admitted, for his advice and encouragement.

\section{REFERENCES}

Crown, S. (1961). Brit. med. J., 2, 1541.

Dornhorst, A. C., Pierce, J. W., and Whimster, I. W. (1954) Lancet, 1, 698

Goetz, R. H.'(1945). Clin. Proc., 4, 337.

Hale, C. H., and Schatzki, R. (1944). Amer. J. Roentgenol., 51,

Herrington, J. L., jun. (1959), Arch. Surg., 78, 17.

Horswell, R. R., Hargrove, M. D., Peete, W. P. J., and Ruffin, J. M (1961). Gastroenterology, 40, 580.

Marshall, I. (1956). New Engl. J. Med., 255, 978.

Pugh, D. G. (1948) Amer. J. med. Sci.. 216, 571

Rosenthal, F. D. (1957). Gastroenterology, 32, 332

Sommerville, R. L., Bargen, J. A., and Pugh, D. G. (1959). Postgrad. Med., 26, 356.

\title{
PARENTAL VISITING OF CHILDREN WITH BURNS
}

\author{
J. M. WOODWARD, P.S.W. \\ Medical Research Council Industrial Injuries and Burns \\ Research Unit, Birmingham Accident Hospital
}

Until recently, parental visiting of child patients in hospital has been very restricted for a variety of reasons. Work in this country, in America, and elsewhere has, however, drawn attention to the emotional damage which small children may suffer as a result of separation from their mothers (Robertson, 1958).

The Ministry of Health (1962) recommended " unrestricted visiting" by parents of child patients in "all types of hospitals"; but in spite of this unrestricted visiting is far from universal.

In many ways burns patients present an extreme form of the difficulties involved. The circumstances of injury are often frightening; the injuries and their treatment are usually painful and frequently there are psychological complications partly due to the very reasonable guilt often felt by the parents. Infection of burns is one of the most serious complications and the most frequent cause of death, so it is understandable that frequent visiting with its possibilities of introducing and spreading infection has often been opposed on the grounds of proper medical care of the patients. However, when Dr. E. J. L. Lowbury made an investigation of Burns Unit patients two years after parental visiting was started, he found there was no increase in the level of infection as a result of the visiting (Lowbury and Jackson, 1960).

In a study of children who had been treated two to five years previously at the Burns Unit of the Birmingham Accident Hospital there was evidence of emotional disturbance in about four-fifths of children with burns of $10 \%$ or more of the body surface (Woodward, 1959). Of all the factors examined in an attempt to analyse the causes, the only one of statistical significance was the lack of parental visiting to children under 5 years of age.
Partly as a result of these findings, twice-daily visiting by parents of patients under 5 years old was started in the Burns Unit in 1958, for the first time.

As this visiting has now been continuous on the Burns Unit for four years, it seemed worth while making a further study to see if this visiting has actually made a positive contribution to the lessening of emotional disturbance in these children and also how much visiting was necessary to be of any benefit.

\section{Investigation Into the Value of Parental Visiting}

The present study was made during 1961-2 and was restricted to children under 5 years of age. Eighty-three children in this age-group survived $10 \%+$ surface area burns during 1958-60. Eight had to be excluded from the study as untraceable; the other 75 were interviewed in their homes. The mothers were asked to give their opinions on the emotional state of their child at the time of discharge and at the interview and also how often they visited their child in hospital. The mother's actual words were recorded in writing and at the end of the interview she was asked if she was willing to sign it as a statement of her own views. This method was used in order to avoid possible bias on the part of the interviewer, since in some cases she knew the mother well and so was aware of her frequency of visiting.

The children were categorized as "frequently visited" if seen once or more a day by their mothers, " infrequently" covered those seen weekly or two or three time a week. "Emotional disturbance" was categorized as in the previous study, according to symptoms as described by the mother.

The accompanying Table shows a statistically significant $\left(\chi^{2}=18 ; \quad \mathrm{P}<0.01\right)$ relationship between frequent parental visiting and lack of disturbance when 